\title{
Influence of the COVID-19 lockdown on remote workers' physical and psychosocial wellbeing and work productivity
}

Yessica Abigail Tronco Hernández, $\mathrm{PhD}^{1}$ - Fabio Parente, $\mathrm{PhD}^{2}$ - Mark A. Faghy, $\mathrm{PhD}^{3}-$ Clare M. P. Roscoe, PhD $^{3}$ - Frances A. Maratos, PhD ${ }^{2}$

${ }^{1}$ School of Health Professions, University of Plymouth, UK

${ }^{2}$ School of Psychology, College of Health, Psychology and Social Care, University of Derby, UK

${ }^{3}$ School of Human Sciences, College of Science and Engineering, University of Derby, UK

Corresponding Author:

Dr Fabio Parente

School of Psychology

College of Health, Psychology and Social Care

University of Derby,

Kedleston Road,

DE22 1GB

Derby, UK

\section{F.parente@derby.ac.uk}

Funding Sources: NONE

Conflict of Interest: NONE DECLARED

Ethical Considerations \& Disclosure(s): The study was approved by the University of Derby's College of Life and Natural Sciences Research Ethics Committee (ETH1920-3136). Participants provided informed consent at the start of the online survey.

\section{Author Note}

Yessica Abigail Tronco Hernández: https://orcid.org/0000-0002-6262-8659

Fabio Parente: https://orcid.org/0000-0003-4789-9511

Mark A. Faghy: https://orcid.org/0000-0002-8163-7032

Clare M. P. Roscoe: https://orcid.org/0000-0002-8146-8531

Frances A. Maratos: https://orcid.org/0000-0001-5738-6491

This is a pre-print of an upcoming publication. For the version of record, refer to the following:

Tronco Hernández, Y. A., Parente, F., Faghy, M. A., Roscoe, C. M. P., Maratos, F. A. Influence of the COVID-19 lockdown on remote workers' physical and psychosocial wellbeing and work productivity. JMIRx Med (forthcoming). doi:10.2196/30708

http://dx.doi.org/10.2196/30708 


\section{Abstract}

Background: Imposed lockdowns during the COVID-19 pandemic have impacted the living and working habits of millions, with potentially important implications for physical, mental, and social wellbeing.

Objectives: The primary objective was to investigate the impact of the pandemic on remote workers not directly affected by the virus.

Methods: This was a correlational cross-sectional study (with an additional qualitative component) of 184 remote workers surveyed during the first COVID-19 lockdown in the UK. Standard measures of mental health (Kessler-6), productivity (IAPT) and physical activity (IPAQ) were used, with respondents further surveyed on changes to their dietary, exercise, smoking, drinking and socialisation habits to produce a 'well-being change index'.

Results: Results revealed associations between sedentary behaviour and poorer mental health $\left(\tau_{b}=.14\right)$ and between poorer mental health and low work productivity ( $\left.\tau_{b}=-.39\right)$. However, both positive and negative lifestyle changes were reported; a self-reported increase in wellbeing (with respect to diet, exercise, smoking, alcohol consumption, and socialisation) since the start of the pandemic was associated with both better mental health $\left(\tau_{b}=-14\right)$ and better work productivity $\left(\tau_{b}=.14\right)$. Of note, we observed rates of moderate $(55 \%)$ and severe $(12 \%)$ psychological distress markedly higher than those reported in large pre-pandemic studies, and $70 \%$ of our respondents reported more sedentary behaviour, 41\% increased their alcohol consumption and 39\% their overall food intake. However, 46\%, 45\% and 52\% reported spending more time walking, engaging in more moderate and vigorous exercise, respectively. Qualitative analysis revealed many positive adaptations to lockdowns (e.g., decreased commuting expenses, flexibility) but also a number of structural obstacles to remote working (e.g., lack of support and high expectations from employers, childcare duties).

Conclusions: These findings may be of practical importance for policy makers and employers in a world of work involving long-term remote or hybrid employment arrangements; strategies to promote more sustainable remote working are discussed.

Keywords: remote working, work productivity, physical and mental wellbeing, diet, exercise, COVID-19 


\section{Introduction}

The COVID-19 pandemic has had catastrophic effects on global economies, with significant reductions in commercial and business activities projected [1], as well as increasing unand under-employment with associated loss of income [2,3]. In a study of Vietnamese remote workers, $61 \%$ of respondents reported losses of income as a result of the country's first national lockdown, with women more financially affected than men [4]. The COVID-19 pandemic has further forced a work strategy paradigm shift in a very short period of time, which does not provide the "flexibility" that home working would offer under normal conditions [5]. In several industries, working remotely has become a prominent solution to continued employment (e.g., higher education delivery; business and operational management; administrative/secretarial etc.) during the pandemic. With uncertainty surrounding the prolonged impacts of COVID-19, and companies accelerating their plans to shift to remote working as a new default $[6,7]$, there is an urgent need to understand the direct and indirect impact of remote working [8]. The impact of such sudden changes to working routines needs to be addressed in an attempt to understand the broad impacts of COVID-19 on work productivity and well-being [9].

In the UK, lockdown and social distancing measures were imposed from March 2020 [10]. By April, almost half of UK employees were working remotely; 90\% of them having transitioned to this form of working because of the lockdown [10]. However, to date, little attention has been directed towards understanding the health, wellbeing, and societal impacts of remote working. This has most likely reflected: 1) the need to increase epidemiological understanding and direct impacts on front-line services and patients; 2) pre-pandemic evidence demonstrating benefits of remote working due to its flexibility [11] and financial convenience [12], and 3) the low risk of those that are working remotely to contract the infection due to reduced social contact and isolation [13]. However, the validity of pre-pandemic evidence is questionable in the current climate where societal and economic issues are profoundly different. Accordingly, this paper will present an insight into the effects of remote working to establish an understanding of the impacts upon physical health, psychosocial wellbeing, and work productivity.

Whilst remote (or distant) working is not a new phenomenon, before 2000 only $2.5 \%$ of UK workers (2/3 of them women) worked remotely. Historically, the logic behind flexible 
work arrangements has been to avoid losing valuable labour to factors such as childcare and family commitments $[5,14]$, as well as to promote a more environmentally friendly way of working (e.g., decreasing resources to commute) $[15,16]$. Wellbeing has been identified as a key factor behind productive remote working $[17,18]$. However, as a consequence of COVID-19, the number of people working remotely in the UK increased to 13.02 million [10]. Thus, there is an urgent need to understand the ramifications of this unprecedented switch in employment type, including resultant wellbeing and productivity lifestyle changes. Whilst wellbeing is a complex and multifactorial state, key facets include diet, exercise (physical health) and mental health $[19,20]$, each linked to societal, economic and mortality issues.

\subsection{Well-being and work productivity}

Mental health disorders account for a significant proportion of the global disease burden and, together with worker burnout, are estimated to cost the global economy over 1 trillion USD per year and 16 trillion USD per year by 2030 [21]. There are already reports of physical and emotional burn-out, and mental health difficulties, amongst medical doctors and nurses $[22,23,24,25]$, as well as social carers [26,27], pointing to a clear link between mental health and work productivity [28]. Holmes and colleagues [29] report that major adverse consequences of the COVID-19 pandemic are likely to be social isolation and loneliness; both of which can lead to depression, anxiety, self-harm and attempted suicide. Social isolation and loneliness could be factors exacerbated by remote working, especially where the switch has been rapid and unexpected. Indeed, Holmes et al. [29] further suggest that working from home, as a consequence of the pandemic, has abruptly interrupted many social opportunities important for physical and psychological health.

Remote working may also allow for greater media consumption, which in turn has been correlated with anxiety and depression amidst the current pandemic [30]. Moreover, following the Ebola crisis, media exposure was found to exacerbate stress responses and worries [31] and messaging on Ebola risks to increase public anxiety [32]. Thus, increased consumption of media during times of crises and pandemics may be a maladaptive coping consequence. For example, Jungmann and Witthöft [33] have reported that both health anxiety and cyberchondria (excessive online information searching), constitute risk factors for COVID-19 anxiety. However, they further observed that adaptive emotion regulation (in 
this particular case, using cognitive emotion regulation strategies to cope with negative life events) protected against COVID-19 anxiety. Consistent with this, in a sample of over 5000 Spanish adults surveyed during the Spanish lock-down, Fullana and colleagues [34] found that consuming a healthy diet and avoiding high consumption of COVID-19 news, predicted lower reports/symptoms of depression and anxiety, as did taking the opportunity to pursue hobbies and engaging with nature (even if just looking outside).

During COVID-19, eating has been shown to be unhealthier, particularly relating to snacks and alcohol consumption [35]. Obesity and its related comorbidities are additionally cited as major risk factors for COVID-19 infection [36,37] and poorer clinical outcomes [38]. Of direct relevance is the recently launched "Better Health" campaign by the UK government, which aims to support actions against COVID-19 and reduce obesity related costs in the NHS ( $€ 6$ billion per year [39]). Hence, diet has a crucial role in preserving health and protecting at risk populations during the COVID-19 pandemic. As such, it is essential to understand how this has changed as a consequence of COVID-19 work pattern changes, including the potential added factor of sedation (i.e., physical inactivity and increased sedentary behaviours).

The World Health Organization (WHO) has classified physical inactivity (6\%) as the fourth leading risk factor of global mortality after hypertension (13\%), smoking (9\%) and diabetes (6\%) [40], and recommends 60 minutes per day of moderate-to-vigorous physical activity for 6-17-year-olds, and 75-150 minutes per week of vigorous or moderate physical activity for adults and the elderly, respectively, including 3 and 2 days per week each of muscle and bone strengthening activities (e.g. resistance training) [41]. COVID-19 has had a major impact on physical activity behaviours, due to movement (even leaving one's residence) and self-isolation restrictions for prolonged periods [42]. Ammar and colleagues [35] report that COVID-19 home confinement has negatively affected all physical activity intensities (light, moderate, vigorous and overall), whilst sedentary behaviours such as sitting, lying down, or screen use (e.g., TV viewing, videogame playing) have increased from 5 to 8 hours per day, despite widespread online access to physical activity training programmes or workouts [43].

Prior to COVID-19 physical inactivity was costly and recognised as the fourth leading cause of mortality by the WHO [44]. For example, in 2013, it was reported that physical inactivity cost healthcare systems around the world $\$ 53.8$ billion [45], with deaths attributable to 
physical inactivity costing a further $\$ 13.7$ billion in productivity losses [46]. Sedentary behaviours (independent of physical inactivity) are further associated with cardiovascular risk factors and increased cardiovascular morbidity and global mortality [47]. Unfortunately, since the start of the COVID-19 crisis, restrictions have removed many opportunities to be physically active and reduce sedentary behaviours. The global ramifications of this are concerning as those individuals who were not active before COVID19, are now at even more risk of cardiometabolic abnormalities, sarcopenia, and frailty in the elderly [48]. This scenario has been referred to as 'two pandemics' - one being COVID19 , and the second consequential pandemic being physical inactivity [46].

In sum, an individual's ability to maintain a healthy diet, physical activity and good mental health have likely been impacted by transitioning to remote working. The pandemic has further added several obstacles to the world of work (e.g., childcare duties given school closures, which could disproportionately affect women) [49]. Consequently, there is an urgent need to better understand how, for those in employment, the abrupt switch to remote working (and, more generally, remote working during a pandemic) has affected mental and physical health, including general patterns of well-being change. These findings will also inform our understanding of the public health implications of a long-term or permanent shift to remote working or hybrid arrangements for many even after the end of the pandemic. As such, our goals were to explore:

1) The relationship between physical activity, mental health, diet, and work productivity during the initial COVID-19 lockdown period.

2) The demographic characteristics associated with varying wellbeing in this population.

3) The perceptions remote workers had of their wellbeing and its influence on work productivity.

\section{Methods}

\subsection{Design}

A correlational design was employed to investigate associations between standard indices of mental health, physical activity and productivity, and ad-hoc measures of changes in physical activity, dietary habits, and smoking habits. Open-ended questions were also 
posed to further probe diet, and a final question asked about perceptions remote workers had of their wellbeing in relation to work productivity.

\subsection{Respondents}

Following ethical approval by the local University, the survey was circulated to adult residents of the UK on social media (i.e., Facebook and Twitter) and through press releases between May $15^{\text {th }}$ and July $6^{\text {th }}, 2020$. The latter date marked the beginning of the first week during which a number of indoor amenities (e.g., museums, places of worship, libraries) and hospitality facilities (cafes, pubs, and restaurants) reopened in England [49].

Between these dates, data was collected from 279 respondents, of whom 207 were remote workers at the time. Of these, 25 respondents did not complete all compulsory aspects and were therefore excluded. This left a final sample of $\mathrm{N}=184$, of whom 167 (90.7\%) were not remote workers before the lockdown (i.e., before March 23 rd, 2020 in the UK). Based on power analysis for a correlational design, assuming $r=0.3$ and with $\alpha=.005$, we estimated $\mathrm{N}=142$ should be sufficient to have .8 power to detect such relationships.

\subsection{Measures}

The survey included quantitative standardised measures of mental health, physical activity, and work productivity as well as an open qualitative question asking respondents to provide any additional information about their lockdown experiences not covered by the questionnaire measures and further quantitative items. These further quantitative items were used to probe dietary habits, socialisation, and activities used as coping mechanisms to preserve wellbeing during the lockdown (see specifically 'Measures of diet and wellbeing change during the lockdown' and 'Socialisation, news consumption and coping strategies').

\section{Kessler-6 Distress Scale}

The Kessler-6 Distress Scale (K6) [51] was administered as a measure of psychological distress. The K6 asks respondents to rate the degree to which, in the past 30 days, they have experienced nervousness, hopelessness, restlessness, depression, and feelings of worthlessness on a 1 (All of the time) to 5 (None of the time) Likert scale. The scale produces a potential score range between 0 and 24 , with scores $\geq 5$ generally considered 
markers of moderate distress and scores of $\geq 13$ considered markers of high psychological distress and serious mental illness [52]. The scale has good internal consistency [51], $\alpha=$ 0.89 .

\section{International Physical Activity Questionnaire}

The short version of the International Physical Activity Questionnaire (IPAQ) for middleaged adults [53,54] was used to measure the degree of physical activity (PA) or sedentarism. The questionnaire asks respondents to estimate: 1) the number of days an individual spent more than 10 minutes walking or engaging in moderate (e.g., cycling, double tennis) and vigorous (e.g., heavy lifting, fast cycling) exercise over the past 7 days; 2) the number of minutes they spent walking or engaging in these activities during the average day over this period, and 3) the number of hours they spent sitting per average day. Physical activity is categorised by intensity and includes 'sedentary' behaviours, as well as 'light', 'moderate' and 'vigorous' physical activity levels. Metabolic Equivalents (METs) are then commonly used to express the intensity of physical activities reported. METs are defined as the ratio of an individual's working metabolic rate relative to their resting metabolic rate. A MET equates with the oxygen consumption required at rest/sitting quietly and is assumed to be $3.5 \mathrm{~mL} / 02 / \mathrm{min} \times \mathrm{kg}$ body weight [55]. Sedentary behaviour (as defined above) is where energy expenditure is less than 1.5 METs [56]. It is suggested that compared with sitting quietly, a person's caloric consumption is three to six times higher when moderately active (3-6 METs) and more than six times higher when vigorously active (>6 METs). The scale has acceptable internal consistency [57], $\alpha=0.60$.

\section{Brief Instrument to Assess Workers' Productivity during a Working Day scale}

Work productivity was assessed using the 'Brief Instrument to Assess Workers' Productivity during a Working Day scale' (IAPT) [58]. This 10-item instrument asks respondents to rate the degree to which they have felt focused, tired/sleepy, confident, productive, annoyed/upset, satisfied, or affected by physical symptoms such as pain or dizziness over the last two hours of work. Ratings are given on a "Not at All" to "Extremely" scale, which is scored between 0 and 4 . This produces an overall score ranging from 0 to 40 points, with higher scores denoting higher productivity. The scale has good split-half reliability $\left(r^{2}=0.86\right)$, good internal consistency $(\alpha=0.80-0.91)$, and high convergent 
validity $\left(\mathrm{r}^{2}=0.86\right)$ with longer instruments such as the Health and Work Performance Questionnaire [59].

\section{Measures of diet and general wellbeing change during the lockdown}

Nine items were used to assess whether respondents had experienced an increase, decrease or no change (three response options) in overall food consumption which included consumption of fruits, vegetables, snacks, treats, takeaways, home cooking, soft drinks and alcoholic drinks. Similarly, four items probed whether the time individuals had spent walking, sitting, or engaging in moderate and vigorous physical activity had changed since the lockdown. respondents were also asked whether they had started or quit smoking since the start of the lockdown, whether the amount they smoked had increased, decreased, or stayed the same. Lastly, respondents were asked whether how much they socialised (including virtually) with others, had increased, decreased, or stayed the same since the lockdown.

Measures of diet and wellbeing change during the lockdown were coded as $0=$ no change, and +1 or -1 for a decrease or increase depending on the item, respectively. The full coding scheme is presented in Table 1. Responses were then aggregated into an index of wellbeing change (WCI) since the start of the lockdown, with scores ranging from -16 to +16 , with higher values typically indicating improved overall general wellbeing.

TABLE 1 - Scoring scheme for the questionnaire items directly probing habit changes since the start of the lockdown.

\begin{tabular}{l|ccc}
\hline Measure & More than before & No change & Less than before \\
\hline Overall food intake & -1 & 0 & 1 \\
Snacks & -1 & 0 & 1 \\
Treats & -1 & 0 & 1 \\
Sugar/Fizzy drinks & -1 & 0 & 1 \\
Alcohol & -1 & 0 & 1 \\
Take-away food & -1 & 0 & 1 \\
Sitting & -1 & 0 & 1 \\
Smoking* & -1 & 0 & 1 \\
Smoking frequency & -1 & 0 & 1 \\
\hline Fruits & 1 & 0 & -1 \\
Vegetables & 1 & 0 & -1 \\
Cooking/Baking & 1 & 0 & -1 \\
Walking & 1 & 0 & -1 \\
Moderate exercise & 1 & 0 & -1 \\
Vigorous exercise & 1 & 0 & -1 \\
Socialising & 1 & 0 & -1 \\
\hline
\end{tabular}


* refers to smoking initiation ("More than before") or cessation ("Less than before") since the start of the lockdown.

\section{Socialisation, news consumption and coping strategies}

Respondents were also asked to estimate the average amount of time (in minutes per day) that they spent socialising with individuals within and outside their household, and the amount of time (minutes per day) they spent consuming news content (in print, online, or on TV/radio). Respondents were further asked to select all the resources and strategies they had engaged in, to maintain their physical and mental wellbeing during the lockdown.

The list of resources and strategies for physical activity included: already owned implements, newly purchased implements, specialised books and magazines, smartphone apps, web pages, TV programmes, and advice from friends and family. This yielded a possible range of counts between 0 and 7 .

The list of resources and strategies for mental wellbeing included: yoga, meditation, prayer and other spiritual practices, counselling, reading, watching TV, playing video games and keeping a diary. Respondents were also given the opportunity to list any further mental wellbeing coping strategies they were employing. These were counted and added to the overall count. This yielded a range of responses between 0 and 13 .

\section{Open-question self-reports}

Respondents were given the opportunity to enter text (3000 characters maximum) to volunteer additional information on any of the aspects probed by the survey (diet, mental health, exercise, and work productivity), or to mention anything not covered by the survey that they felt was relevant to their experiences of wellbeing changes during the COVID-19 lockdown.

\section{Demographics}

Lastly, respondents were asked several demographic (age group, gender, educational attainment) and household questions (marital status, whether they had adult or underage children, whether they lived with other adults). 


\subsection{Procedure}

Following informed consent, respondents selected a six-digit alphanumeric code used to anonymise their data and allow for retrieval. They were then presented with, in order: items/questionnaires regarding work productivity (IAPT), dietary changes, mental health (K6), physical activity (IPAQ), exercise resources and coping strategies. These were followed by the optional open-ended question and, finally, the demographics questions.

\subsection{Data analysis}

Kolmogorov-Smirnov tests of normality were conducted on key measures (IAPT, K6, WCI, METs and Sitting Time); all significantly deviated from normality $(\mathrm{p}<.05)$. Visual inspection of the correlation plots for these measures additionally revealed substantial non-linearity in the relationship between several of them. For this reason, Kendall's $\tau_{b}$ correlations were performed to detect statistically significant relationships between psychophysical wellbeing and productivity. Independent-sample Mann-Whitney U-tests and Chi-square analyses were used to test for differences in exercise habits, mental health scores and productivity between demographics (focusing on gender differences and childcare responsibilities). Missing cases were excluded pairwise, to maximise the amount of data available for analysis.

The open-ended question responses were analysed using conventional content analysis [60], conducted by YATH and following the eight steps suggested by Zhang and Wildemuth [61], which involved preparing data, coding texts and making inferences from meanings of the data. This allowed for the observation of trends in respondents opinions. To increase the trustworthiness of the data, triangulation was conducted with the quantitative results, reflexivity was included across data collection and analysis, as well as peer debriefing with other members of the research team [62]. 


\section{Results}

\subsection{Relationship between physical activity, dietary and wellbeing changes, mental health, and productivity.}

Descriptive statistics for standardised measures of productivity (IAPT), mental health (K6), physical activity (IPAQ, expressed in METs), time spent sitting, and wellbeing change since the lockdown (WCI) are presented in Table 2. Figure 1 shows the distribution of responses for the WCI components.

TABLE 2 - Descriptive statistics for the assessed measures of physical activity (IPAQ METs), sitting time (hours per average day), mental health (K6), work productivity (IAPT), and wellbeing change (WCI).

\begin{tabular}{l|c|c|c|c|c|c|c} 
Measure & Min. & Max. & IQR & Mean & S.E. & L.CI 95\% & U.CI 95\% \\
\hline IAPT & 1 & 39 & 11 & 21.61 & .511 & 20.60 & 22.62 \\
K6 & 0 & 24 & 7 & 6.94 & .361 & 6.23 & 7.65 \\
WCI & -10 & 12 & 7 & -.28 & .310 & -.89 & .33 \\
Vigorous METs & 0 & 5040 & 1440 & 827.17 & 75.95 & 677.31 & 977.04 \\
Moderate METs & 0 & 3840 & 360 & 286.80 & 39.90 & 208.08 & 365.53 \\
Walking METs & 0 & 3465 & 610.50 & 645.87 & 44.19 & 558.68 & 733.06 \\
Total METs & 0 & 6993 & 2033.88 & 1759.85 & 104.41 & 1553.83 & 1965.86 \\
Sitting Time & 2 & 18.0 & 3.0 & 8.81 & .238 & 8.34 & 9.28 \\
\hline
\end{tabular}

An initial round of one-tailed correlations (with alpha level set at $p<.005$ ) was computed between respondents' productivity scores (IAPT), their mental health scores (K6), the aggregated wellbeing change index (WCI), the MET measures derived from the IPAQ, and the reported time spent sitting. The results are reported in Table 3 (rows 1-8) and suggest a relationship between sedentarism, poorer mental health, a decrease in wellbeing, and productivity. Namely, the more time respondents reported spending sitting, the worse their mental health scores (K6) and the lower their productivity (IAPT); similarly, a decrease in reported wellbeing since the start of the lockdown (WCI) was associated with worse productivity and poorer mental health. 


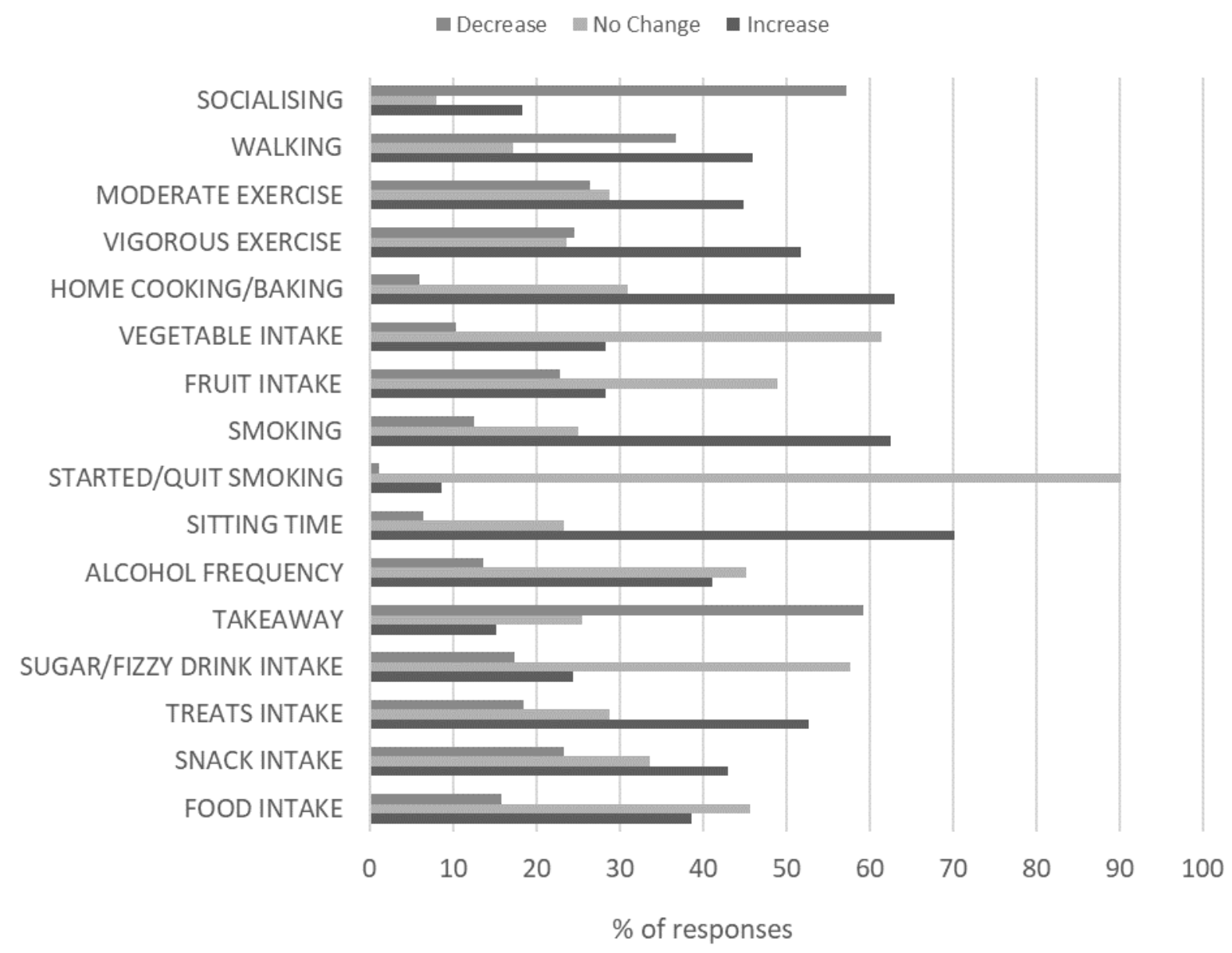

FIGURE 1 - Respondents' reported changes in dietary habits, physical activity, socialisation, and general wellbeing as a function of lock-down (metrics computed following the scheme in Table 1). Bars indicate the percentages of the samples reporting a decrease (top bar in each cluster), increase (bottom bar), or no change (middle bar).

Given the observed relationship between physical activity, mental wellbeing, and productivity, we tested for differences in the above measures between individuals with and without a reported pre-existing mental health diagnosis $(\mathrm{N}=45 ; 24.4 \%$ and $\mathrm{N}=137$; $74.4 \%$ respectively, as 2 respondents did not provide this information). The results of the independent-sample Mann-Whitney U-test are reported in Table 4. As expected, those with a previous mental health diagnosis reported significantly worse mental health, engaged in significantly less vigorous exercise, and spent more time sitting than those without a preexisting diagnosis. 
Excluding the subset of respondents with a pre-existing mental health diagnosis $180 \%$ of whom had K6 scores $\geq 5$ and $22.2 \% \geq 13$ ), 55.5\% of the remaining respondents had scores consistent with moderate distress and $12.4 \%$ with severe distress. For context, a survey of over 50,000 non-institutionalised Californian adults under non-pandemic conditions [52] yielded incidences of $27.9 \% \geq 5$ and $8.6 \% \geq 13$.

TABLE 3 - Results of both rounds of Kendall's tb correlations between productivity (IAPT), mental health (K6), IAPT METs, Sitting Time, resources for physical activity, and general coping activities. Correlation $\mathrm{p}$ values are shown above the diagonal. News intake (minutes per average day) and total time spent socialising (within and outside the household) did not produce any significant correlations $($ at $\mathrm{p}<.005)$ and were therefore excluded from the table.

\begin{tabular}{|c|c|c|c|c|c|c|c|c|c|c|}
\hline Measure & 1 & 2 & 3 & 4 & 5 & 6 & 7 & 8 & 9 & 10 \\
\hline 1. IAPT & - & $<.001$ & $<.001$ & .240 & .095 & .019 & .038 & .022 & .432 & .088 \\
\hline 2. K6 & $-.393^{*}$ & - & .003 & .069 & .027 & .025 & .009 & .003 & .190 & .054 \\
\hline 3. WCI & $.178^{*}$ & $-.148^{\circ}$ & - & .005 & .496 & .023 & .005 & .036 & .025 & .309 \\
\hline 4. Vig. METs & .038 & -.081 & .143 & - & $<.001$ & .144 & $<.001$ & $<.001$ & $<.001$ & .262 \\
\hline 5. Mod. METs & .073 & -.108 & .001 & $.224^{*}$ & - & .312 & $<.001$ & .001 & .005 & .153 \\
\hline 6. Walk. METs & .108 & -.102 & .105 & .057 & .027 & - & $<.001$ & .006 & .378 & .448 \\
\hline 7. Total METs & .090 & -.121 & .133 & $.646^{*}$ & $.379 *$ & $.361^{*}$ & - & $<.001$ & .003 & .442 \\
\hline 8. Sitting time & -.107 & $.147^{\circ}$ & -.097 & $-.256^{*}$ & $-.180^{\circ}$ & -.134 & $-.269 *$ & - & .008 & .106 \\
\hline 9. Exercise Res. & .010 & .050 & .112 & $.219^{*}$ & .157 & -.018 & $.151^{\circ}$ & -.139 & - & $<.001$ \\
\hline $\begin{array}{l}\text { 10. Coping } \\
\text { Activities }\end{array}$ & -.074 & .089 & .028 & .036 & .060 & -.007 & .008 & -.070 & $.240^{*}$ & - \\
\hline
\end{tabular}


TABLE 4 - Physical activity (IPAQ METs and sitting time), mental wellbeing (K6), wellbeing change (WCI), and productivity (IAPT) measures compared between respondents with or without a mental health diagnosis.

\begin{tabular}{l|ccccc}
\hline \multicolumn{7}{c}{ Pre-existing Diagnosis } \\
\hline & $\begin{array}{c}\text { Yes } \\
\text { (Mean Rank) }\end{array}$ & $\begin{array}{c}\text { No } \\
\text { (Mean Rank) }\end{array}$ & $\mathrm{u}$ & $\mathrm{z}$ & $p$ \\
\hline IAPT & 78.97 & 95.62 & 2518.50 & -1.84 & .066 \\
K6 & 116.10 & 83.42 & 1975.50 & -3.62 & $<.001^{*}$ \\
WCI & 84.03 & 93.95 & 2746.50 & -1.10 & .272 \\
Vigorous METs & 71.27 & 98.15 & 2172.00 & -3.07 & $.002^{\circ}$ \\
Moderate METs & 87.52 & 92.81 & 2903.50 & -.63 & .526 \\
Walking METs & 95.60 & 90.15 & 2898.00 & -.60 & .546 \\
Total METs & 82.99 & 94.30 & 2699.50 & -1.24 & .212 \\
Sitting Time & 111.49 & 84.22 & 2138.00 & -3.05 & $.002^{\circ}$ \\
\hline
\end{tabular}

${ }^{\circ}<.005 ; *<.001$

\subsection{Supplementary Analyses}

\section{Socialisation and Coping Strategies}

To gain a better understanding of how respondents were affected by lockdown social restrictions and how these related to coping strategies, including resources individuals employed to maintain physical and mental wellbeing, we performed a second round of correlations (with alpha level again set at $\mathrm{p}<.005$; Table 3, rows 9-13). As such, correlations were computed for work productivity and mental health scores, respondents physical activity (MET) scores and the reported sitting time (see Table 2 for descriptive statistics), together with the total number of physical activity resources (median $=1, \mathrm{SD}=$ 1.15 ) and general coping activities (median $=3, \mathrm{SD}=1.78$ ) respondents reported using or engaging in, the total amount of time they reported socialising with people within (Mean = 192.8 minutes, $\mathrm{SE}=15.4)$ and outside $($ Mean $=78.9$ minutes, $\mathrm{SE}=6.15)$ their household, and their news intake $($ Mean $=50$ minutes, $\mathrm{SE}=4.04)$. These revealed no significant relationship between time spent socialising and any further measures, but a significant relationship between the amount of vigorous exercise and the number of resources used for exercise.

Table 5 shows what part of our sample reported engaging in the different coping activities we provided. Respondents also had the option of mentioning activities not included on the 
list; among the most frequent responses they provided were arts, crafts, and general DIY (19\%), gardening (8.69\%), and cooking/baking (7\%).

TABLE 5 - Percentage of respondents who reported engaging in different coping activities to maintain their psychophysical wellbeing.

\begin{tabular}{c|c}
\hline Activity & \% of sample \\
\hline Yoga & $32.1 \%$ \\
Meditation & $16.3 \%$ \\
Prayer / spiritual practices & $6.5 \%$ \\
Counselling / Therapy & $6.5 \%$ \\
Reading & $61.4 \%$ \\
Watching TV & $77.1 \%$ \\
Playing videogames & $23.9 \%$ \\
Keeping a diary & $7.6 \%$ \\
Other & $33.6 \%$ \\
\hline
\end{tabular}

\section{Household and Gender Differences}

Next, we aimed to investigate whether key demographic factors influenced respondents' psychophysical and social wellbeing during the lockdown, as well as their coping strategies.

Here, we compared by way of independent-sample Mann-Whitney U-test key measures between respondents from households with $(\mathrm{N}=46)$ and without $(\mathrm{N}=136)$ children under the age of 18 years. The results are reported in Table 6. Adults living in households with children reported, on average, approximately 2 hours less of sitting time and reported resorting to fewer recreational activities to maintain their psychosocial wellbeing. No other difference (e.g., in mental health or productivity scores) achieved significance at the .005 alpha level.

Comparing the same measures as in Table 6 between men $(N=40)$ and women $(N=143)$, similarly revealed women reported engaging in more recreational activities than men (mean ranks 63.06 and 100.09 respectively) to maintain their psychosocial wellbeing, $\mathrm{U}=$ $1702, \mathrm{z}=-3.98, p=<.001$. Women were also significantly more likely than men to report being the main childcare, $\chi^{2}(2)=17.08, \varphi_{c}=.609, p<.001$, and home schooling, $\chi^{2}(2)=$ 9.21, $\varphi_{\mathrm{c}}=.458 . p=.01$, providers in the household. No significant gender differences were found in the total number of physical activity resources that respondents reported using, $p$ $>.1$. 
TABLE 6 - Physical activity, mental wellbeing, and productivity measures of respondents with and without children under 18 years.

\begin{tabular}{l|ccccc}
\hline \multicolumn{7}{c}{ Underage Children in Household } \\
\hline & $\begin{array}{c}\text { Yes } \\
\text { (Mean Rank) }\end{array}$ & $\begin{array}{c}\text { No } \\
\text { (Mean Rank) }\end{array}$ & $\mathrm{u}$ & $\mathrm{z}$ & $p$ \\
\hline IAPT & 95.26 & 90.23 & 2955.00 & -.561 & .57 \\
K6 & 84.48 & 93.88 & 2805.00 & -1.04 & .29 \\
WCI & 92.13 & 91.29 & 3099.00 & -.094 & .92 \\
Socialisation (In) & 102.44 & 82.36 & 2042.50 & -2.23 & .02 \\
Socialisation (Out) & 88.48 & 90.51 & 2946.50 & -.23 & .81 \\
News Intake & 79.47 & 92.70 & 2471.00 & -1.48 & .13 \\
Coping Activ. & 64.64 & 100.58 & 1892.50 & -4.07 & $<.001^{*}$ \\
Vigorous METs & 80.79 & 95.12 & 2635.50 & -1.65 & .09 \\
Moderate METs & 87.61 & 92.82 & 2949.00 & -.63 & .52 \\
Walking METs & 92.58 & 91.14 & 3078.50 & -.16 & .87 \\
Total METs & 79.87 & 95.46 & 2589.00 & -1.74 & .08 \\
Sitting Time & 64.10 & 100.17 & 1867.50 & -4.06 & $<.001^{*}$ \\
\hline$*<.001$ & \multicolumn{7}{c}{}
\end{tabular}

$*<.001$

\subsection{Qualitative Self-Report Data}

Three themes emerged from the content data analysis related to different aspects of remote working. These were "Barriers to remote working and wellbeing preservation", "Mixed feelings and attitudes towards remote working" and "Aids to improve physical and psychosocial wellbeing". This section presents a narrative analysis of these themes with supporting illustrative respondent extracts.

\section{Theme 1: Barriers to remote working and wellbeing preservation}

This theme dealt with aspects of the lockdown that represented limitations to working and maintaining health and wellbeing at standards individuals would have liked. Some respondents mentioned childcare responsibilities as a constraint, others mentioned how their eating habits had worsened, and some respondents reported difficulties in engaging with remote working.

Various respondents that were engaged in childcare duties described how stressful and tiring their work responsibilities were, and how challenging it was to take care of themselves (health wise). 
"I have struggled to separate work and home learning with children" (R9)

“...but have an 18-month-old also at home full time so productivity goes out the window; we have to organise our diaries at the start of the day so that we can pass her back and forth between us" (R23)

"I have however been very unproductive work-wise, as my husband is still working full time and I have 2 young children to home school" (R31)

"I have a child (3 years old) and having him off nursery [...] dramatic impact on my mental health as I struggle to move from "mum mode" into "work mode" and has an impact about how I feel about my lack of work achievement - this then becomes a cycle of feeling as though I'm not achieving anything along with feeling mum guilt for not being with my son" (R51)

Respondents who reported having teaching and pastoral occupations recorded feeling more tired, stressed, and anxious. Moreover, there was an overall fear of losing their job and of not being "as productive" as expected if they could not adapt successfully to working from home.

"...my concentration is poor and online teaching is tiring, I feel concerned that I have to perform at even higher level to ensure the student get the best from me" (R3)

"I feel l am working harder to prove myself to my employers as I do not want to lose my job. This has resulted in me becoming run down and ill [...] I did not take any time off during this time" (R4)

"Yet I believe I am near to cracking trying to do a full day's work with the distraction of the virus is really difficult" (R14)

Furthermore, respondents had an overall negative perception of the change in their eating habits and tended to comment on alcohol and sweet foods consumption, more than other foods. 
"I try not to eat from boredom or comfort eat (sic) but I'm not really succeeding. I also drink more alcohol and fizzy drinks, going from almost never to a couple of times a week. I had cut out snacks and drinks like these almost completely in an attempt to lose weight before lockdown, but I feel like the joy of snacking and drinking is more important than losing weight right now" (R7)

"My appetite is definitely less. I often go without breakfast and have a very small lunch However, I can binge eat more than before. For example, when I bake, I will eat all that I have made within a day" (R22)

Lastly, aspects that were not explored in the survey emerged as potential barriers to psychological wellbeing. Some activities that respondents considered beneficial to limit, included time spent on news intake and visits to supermarkets. Additionally, lockdown restrictions to exercising were mentioned as problematic.

"I have become increasingly anxious when in shops because people are increasingly forgetting to keep their distance" (R1)

"I find news and (sic) media very worrying and negative. I find that sometimes I feel ok and maybe even positive and then I'll read a bad statistic online or see news headlines and it ruins my mood." (R11)

“Only being able to exercise once a day was a real issue as it made me feel restricted. My running has reduced due to nervousness about going out and bumping into others as local parks etc have become increasingly busy with other people" (R8)

"I have been confined to my flat, either sitting or lying down most of the times. The restrictions have left me unable to walk as much as I always did before" (R10)

This theme reveals that the lockdown caused various disruptions to the personal lives of those performing their work duties remotely, including the negative effects of balancing childcare; and their employment fears, which included not performing to "acceptable" standards. Eating habit concerns were also noted, including a report of 'binge' and/or 
RUNNING HEAD: WELLBEING AND WORKER PRODUCTIVITY DURING LOCKDOWNS

'comfort' eating. Furthermore, challenges affecting mental health were described as key wellbeing antecedents (and vice versa).

\section{Theme 2: Mixed feelings and attitudes towards remote working}

It was clear that attitudes towards remote working depended on personal circumstances and a link between physical health and mental states was observed across narrations. This seemed to also influence what respondents recognised as the challenges or advantages of their remote working dynamic. Physical activity needs, as well as mental health struggles, were reported as challenges. A pattern of more tiredness and lack of sleep during the lockdown were major trends reported amongst respondents. A lack of ergonomic aids or efficient IT resources and the "overuse" of technologies were also reported to negatively impact mental health. Some impracticalities of working from home were reported:

"[...] however, everything had to change overnight and that takes time to get right! It has been exhausting, mentally exhausting. I miss the little breaks, walking to a meeting, popping to coffee shop" (R5)

"I am not working as much in the evenings and at weekends. I am behind, though, on my work. In the first couple of weeks of lockdown, I found it difficult to concentrate, adapt, sleep, keep working. I find it hard to mark work online and am fed up of (sic) looking at a computer screen. [...] Work online takes about three times as long" (R18)

"The physical difficulties associated with using a dining table desk set-up without proper office equipment (I have an occupational health assessed ergonomic chair at work) have added another layer of challenge" (R63)

"From a personal point of view, I was doing well with exercise but have had some injuries and felt unwell at times. I've felt more tired than usual regularly too" (R37)

"Sleep worse than before, cannot switch off at night-time. Have switched from listening to radio 4 to go to sleep to Radio 3 as felt it was constantly information about COVID19" (R59) 
For some, the switch to homeworking had limited opportunities for physical activity and blurred the line between work and home life. Several respondents, however, pointed out that a more flexible work dynamic and trust from their employers gave them a greater sense of ownership.

"It suits me working more flexibility (sic), my blood pressure is lower, and I have less headaches. [...]" (R5)

"the lockdown has not had a negative impact on mental health and has had a positive impact on physical health as we are doing more exercise" (R17)

"Working from home has allowed me to reclaim a few more hours for myself, now that I'm not commuting, and I've been finding ways to make sure that I'm using that time to create a good work /life balance" (R19)

"I am pleased to say that the quality of my life has significantly improved since the COVID outbreak and consequent lockdown. This is because I can work from home and more flexibly, without having to commute and drive/use public transport between cities." (R57)

Several respondents further reported some benefits in their physical health and quality of life or work life balance.

In sum, this theme demonstrates that remote working has had both benefits and disadvantages on the work dynamic of respondents, and how they perceive their work-life balance, personal lives and physical and mental health; all of which are key for wellbeing.

\section{Theme 3: Aids to improve physical and psychosocial wellbeing}

This theme focused on various activities and aspects that positively benefited the physical and psychosocial wellbeing of respondents. Gardening and DIY activities were cited as hobbies that helped respondents to cope with the current stressful situation:

"We are still trying to keep active, get fresh air and do DIY at home to balance the body and mind." (R29) 
"Spending more time in the garden which helps to relax, spending more time with pets, learned (sic) new hobbies." (R46)

"I have tried to keep myself as active as possible, doing work around the house/garden." (R48)

Some of the most mentioned benefits of going through this unique circumstance were increasing spirituality, having more contact with nature and self-reflection on life goals, valuing family or a partner's physical presence, discovering new skills and hobbies, and positive use of the saved time and resources by non-commuting:

"[...] although it has helped me to focus more on myself (sic) and the things that truly matter" (R10)

"I have still found some elements of lockdown beneficial particularly in the slower pace of life, which has made me think that I may want to keep some aspects of my new routine to improve my mental health when things go back to 'normal'" (R16)

"I am grateful for the space in our home, for living with my partner, in the countryside and still being able to go outside. I think I appreciate the 'small' things more" (R34)

"I can save money on not having to commute, which helps me because I am the only earner in my household" (R57)

To sum, this theme encompasses some stressful situations circumvented by the lockdown that was not considered in the closed questions. It additionally identifies coping strategies that several respondents had been employing during the lockdown that had positively influenced their psychosocial wellbeing.

\section{Discussion}

The purpose of the present study was three-fold. Firstly, we set out to investigate the relationship between physical and psychosocial wellbeing and work productivity under lockdown conditions that were imposed as a result of COVID-19. Secondly, we explored whether remote workers with different demographic profiles (e.g., gender, parental duties) 
were differentially affected by lockdown and home-working conditions, with respect to their wellbeing and work productivity. Finally, we aimed to explore remote workers' perceptions of the lockdown; specifically, its effects on their work productivity and wellbeing. Key results included: i) the observation of significant relationships between sedentary behaviour and poorer mental health, which were in turn related to worse work productivity. ii) Exacerbation of these relationships as a consequence of poorer mental health. iii) Self-reports of childcare responsibilities (particularly for women), unhealthier diets, work-life balance and home-working environment as barriers to remote working productivity and mental health; iv) Self-reports of potential aids and benefits during the lockdown, that researchers, employees, policy makers etc. can learn from when considering home-working practices. These will now be discussed in turn.

Correlational analyses revealed significant relationships between sedentary behaviour (i.e., time spent sitting, which in turn, negatively correlated with physical activity expressed as IPAQ METs) and poorer mental health, which was further related to worse work productivity. To expand, we observed associations between work productivity, mental health, and changes in wellbeing. For example, we found that higher mental distress scores (K6) were correlated with worse work productivity (IAPT) and worsened wellbeing (WCI) since the start of the UK lockdown. This is consistent with existing evidence associating work performance and productivity with wellbeing under non-lockdown conditions $[18,19]$ and demonstrates that the links between physical and mental health observed before the pandemic still explain variation in these measures and work productivity. It also suggests that recommendations to support remote working that have been proposed in light of past research (e.g., adequate IT support, clear communication between staff and management regarding outcomes [18]) still have the potential to be applied in the current situation to improve the productivity of remote workers. Similarly, the current circumstances should prompt broader discussion and policy development concerning the uptake of technology to enable the remote provision of mental healthcare [63].

Notably, the rates of moderate (55\%) and severe (12\%) psychological distress were substantially higher in respondents without a mental health diagnosis than has been previously observed in large samples during non-pandemic periods [52] and disasters such as nuclear accidents and earthquakes [64]. While an element of participant self-selection may explain the extremely high rates of psychological distress we observed, we cannot 
exclude that the unprecedented magnitude of the ongoing Coronavirus crisis and the prolonged restrictions in many countries like the UK may be the catalyst for such pronounced decreases in psychological wellbeing reported.

A further major finding of the current research was that individuals who had received a mental health diagnosis before the lockdown had significantly worse mental health scores, and spent significantly more time sitting, than individuals without a diagnosis. Previous research has identified stress, depression, and anxiety as key predictors of absenteeism (13.8k days lost per annum) in the UK, resulting in a 6\% decrease in productivity [65]. Mental health issues have been reported to affect fundamental aspects of work-life balance [28], and to increase absenteeism and presenteeism [66]. Economic losses as a result of poor mental health have also been documented, further justifying research into costeffective occupational and psychosocial interventions [67]. Thus, the present findings point to the prevalence of previous and new mental health issues as a crucial consideration of the COVID-19 pandemic, not only for public policy makers when considering management of societal recovery from the pandemic, but also for the private sector to maintain viable working environments. This includes promoting the importance of good wellbeing and services available that employees can access (without stigma).

Psychological distress and poor mental health, nonetheless, can affect more than just work productivity, and in turn, be affected by a variety of environmental stressors. The narrative self-reports revealed that several aspects of respondents' daily lives during the pandemic (e.g., changes to shopping habits and lack of contact with relatives and friends) interacted with other sources of stress or anxiety, which individuals related to poorer mental health. Fear, stress, tiredness, and lack of sleep were widely reported across narrations; and news intake appeared to add to worries and stress. This accords with existing research showing that media and risk-elevating message exposure exacerbated stress, worries and public anxiety [31,32], but also that news intake correlated with poor mental health in the UK, particularly at the beginning of the pandemic [30]. Interestingly, however, news intake did not appear to produce significant correlations with mental health (K6) scores, nor overall wellbeing change (WCI), although it was correlated with work productivity and was represented as a concern across qualitative comments. As such, other aspects of news consumption not probed in the present survey (e.g., how many times per day news is watched; preferred news source or news media type etc.) may be more informative in 
understanding its effects on mental health, as opposed to simply the number of minutes dedicated to viewing news reports during an average day.

The majority of respondents in our sample (70\%) also reported spending a greater amount of time sitting, compared to before lockdown restrictions came into effect. Decreasing physical activity for various respondents was partly due to the initial restrictions to outdoor exercise. These findings are important, as even before COVID-19, physical inactivity and sedentary behaviour were a suggested pandemic in their own right, with $31 \%$ of individuals 15 years or older being identified as physically inactive; and approximately 3.2 million deaths per year attributed to these types of behaviour [68]. Thus, strategies to circumvent sedation need to be promoted. Encouragingly, however, portions of our sample reported walking more (46\%) and engaging in more moderate (45\%) and vigorous (52\%) exercise.

Similarly, substantial proportions of our sample reported an increase in smoking (63\%), alcohol (41\%) and overall food intake (39\%), including sweet treats (53\%) and savoury snacks (43\%), consistent with existing research [34] showing more snacking and unhealthy food choices in the general population across the world during the COVID-19 pandemic. However, we also observed increases in vegetable intake (28\%) and home-cooking (63\%), and a decrease in takeaway use (59\%). Our qualitative data suggest these positive health changes may represent attempts at coping with life and work stressors during the lockdown, a result of more time available, and/or increased awareness of the ill effects of a poor lifestyle, particularly in the context of COVID-19, which have been widely documented during the pandemic $[34,38]$.

Regarding physical activity, our data revealed that some respondents had more time to engage in indoor physical activity than before the lockdown. There is evidence of growing public awareness of the importance of physical activity than ever before $[69,70]$. Fitness centres have posted free online workouts to promote physical activity [43] and information about examples of exercises that can be done at home has been disseminated [71,72]. This includes practical recommendations for aerobic exercise, bodyweight exercises, dance, and active video gaming, as a means to promote physical activity and protect individuals both physically and mentally from COVID-19 [42]. The WHO further highlights how adults and children can achieve the recommended physical activity guidelines at home, with no special equipment and limited space [41]. These recommendations in home-based activities may 
have been paramount in ensuring some individuals remained physically active and reduced engagement in sedentary behaviours.

We also explored gender and household characteristics as potential sources of differences in wellbeing and productivity. Adults living in a household without underage children were significantly more sedentary and, whilst they engaged in more coping activities, did not significantly differ on any other metrics as compared to the rest of the sample. More importantly, and consistent with recent research [5], we observed that women were significantly more likely to be the main childcare providers in the household. Whilst quantitative analyses did not reveal any significant gender differences in mental health or productivity as a consequence of gender, our qualitative data pointed to childcare duties as a significant challenge for adults - particularly women - attempting to maintain their wellbeing. These childcare responsibilities which women reported, proved an obstacle to optimal work functioning. However, we did observe that women, as compared to men, reported engaging in more recreational activities (e.g., cooking/baking, arts and crafts, gardening) in an attempt to preserve their psychological wellbeing. This could explain why, despite women reporting the challenges of childcare to their psychological health, the quantitative analysis did not reveal differences in wellbeing as a function of gender. Notably, given the wealth of evidence for existing gender inequalities $[9,73,74,75]$, research on psychophysical wellbeing and employment outcomes in remote workers in the aftermath of the pandemic should consider gender an important factor [76]. To circumvent the negative effects of remote working, some of the recreational activities respondents in our sample resorted to (e.g., gardening, or meditation) could be further researched as effective strategies to promote good coping/wellbeing during lockdowns, e.g., connecting with nature (for a review see Richardson and colleagues [77]) or embracing a more selfcompassionate mindset (for a meta-analysis see Wilson and colleagues [78]).

Difficulties with maintaining work-life balance were a recurring theme in our qualitative data, yet a more flexible work dynamic and an improved work-life balance were reported in some narrations. Past research [73] has found that voluntary remote working increases work-life balance, observing that remote working could preserve wellbeing as long as workers can be flexible about it (which is challenging during a lockdown). Mustajab and colleagues [5] further reported a lack of commuting as an advantage of remote working in their sample of Indonesian workers. These findings accord with some of our narrations. 
However, some of our respondents reported that they were working more hours despite the time saved by not commuting (see also Béland and colleagues [13]). Additionally, and concerningly, respondents in our survey further reported expectations of productivity levels on the part of their employers often higher than required pre-lockdown. While flexible employment has previously been found to increase productivity [79], past research did not account for the added stressors of a global pandemic and resulting lockdown (nor autonomy of choice - or lack thereof - to work remotely). An important question leading on from this research is whether the perceived productivity expectation was a requirement of a respondent's role or a self-assumed expectation. Either way, it has important ramifications regarding employer-employment communications in pandemic and remoteworking situations, especially as high-pressure, high-performance work cultures can lead to poorer mental health and staff retention issues $[73,80]$.

Finally, whilst the International Labour Organisation [81] has identified remote working as an excellent strategy to mitigate job losses, and calls for policies aimed at protecting workers by supplementing their income [82] and encouraging flexible work arrangements [3], many of our respondents reported complications regarding technologies, equipment and the use of living spaces as a new workplace, which affected their attitudes towards work [83] as well as their ability to work. Such findings are again consistent with existing research [5] indicating a breakdown of communication with managers and colleagues as a common COVID-19 complaint. Thus, adjusting to the new realities of remote work materially, socially, and psychologically - appears to pose challenges across national economies and cultures.

In summary, currently, there is scant evidence in the literature concerning remote workers' perceptions of the lockdown's effects on their physical and psychosocial state and how this might affect their work productivity. This is especially the case for those who were required to transition to remote work during a global pandemic (many of them without being accustomed to this mode of working [83]). However, our qualitative data highlight a range of concerns on the part of respondents from childcare to perceived work pressures, to the practicalities of physically being able to work effectively from home - all of which map onto employment prospects. Notably, employment prospects have been shown to affect mental health, satisfaction, and sense of identity [84], all of which are pillars of psychological wellbeing [85]. Given the observed relationship between psychological stress 
and poor work productivity reported by our participants (but also demonstrated via our quantitative data), the current state of affairs for many remote workers could create a negative feedback loop. To expand, the enforced move to remote working, for many, has created work-related uncertainty and pressures - negatively affecting mental health. The latter, in turn, could then further affect work productivity, exacerbating work-related concerns and, consequently, mental health. Thus, a downward physical, psychological, and work productivity spiral perpetuates.

\section{Implications}

The present study contributes to a nascent field investigating the wellbeing of remote workers, and how remote working can be enhanced. The pandemic recovery process will likely involve a variable period of flexible work arrangements, as some employers may struggle to adapt their workspaces to comply with continued social distancing regulations [86] and some workers might prefer to continue working remotely or via a hybrid officehome model [87]. Importantly, a study [88] conducted among Chinese workers returning to office-based employment following the lifting of restrictions found that $\sim 10 \%$ of respondents reported symptoms consistent with a diagnosis of post-traumatic stress disorder. The study found that the incidence of psychiatric symptoms were, among others, the presence of physical symptoms, poor physical health, and a negative perception of a return to the workplace. However, the study also found that the implementation of workplace hygiene and prevention measures (e.g., mask-wearing policies) on the part of employers was related to less severe psychiatric symptoms. In light of this, employers, institutional policies, and governments must address the issue affecting workers - both those returning to the workplace, and perceived vulnerabilities/anxieties this might pose to employees, and those who will continue to work remotely for the foreseeable future. For all modes of working (be it office-based, home-based, or hybrid), all technological and ergonomic aids should be already in place for remote workers to work as close as possible to their original conditions [83]. Where this is not occurring or cannot be expedited, support structures must be put into place, with employers recognising that work productivity, rather than increasing, may in the first instance decrease.

Secondly, childcare responsibilities need greater consideration. Various guidelines have been published to deal with childcare responsibilities $[89,90]$, and calls have been made to 
support working parents (especially women) in remaining in employment [91]. Current strategies across the world, however, prioritise changes to individual behaviours, without considering the potential impact that employers and working conditions have on worker wellbeing or the personal circumstances of employees. In light of the relationship between wellbeing and productivity, it is in the best interest of both workers and employers to consider systemic obstacles to wellbeing and systemic solutions to them. Expectations of high productivity imposed on workers trying to juggle parental as well as teaching duties while remote working during a time of ongoing or potential school closures can dramatically worsen gender inequalities [91]. Employers should acknowledge the considerable physical and psychological burden on primary child carers (overwhelmingly women) who are balancing remote working with child-care (including home tutoring) responsibilities and implement strategies accordingly.

Dietary recommendations in light of the COVID-19 pandemic [92,93] and particularly for people in lockdown have not been widely formulated and disseminated. Our data revealed increases in overall food intake, specifically the increased consumption of sweet treats and savoury snacks and increased frequency of alcohol consumption. However, respondents also reported decreases in takeaway use and increases in home cooking, suggesting there is potential to make remote working a sustainable and healthy lifestyle provided individual and systemic obstacles are investigated and tackled. For example, recent evidence has favoured the idea of promoting immunonutrition, rather than only healthy eating, during the current pandemic $[94,95]$. Although the "Better Health" campaign in the UK attempts to tackle some systemic barriers, tailoring information that encourages sustainability of a healthy diet across society by guaranteeing access to essential nutrients through healthy eating and/or vitamin supplements, is still needed.

Finally, our data points to a clear mental health crisis unfolding in remote workers, which may engender and be engendered by sedentarism and poor nutrition, and in turn negatively affect work productivity. Public health guidelines for clear and effective actions are needed to improve psychophysical wellbeing and promote health, thereby also potentially increasing work productivity in the home-working population. There is no shortage of published research to inform such policies in the context of improved nutrition [96,97], exercise [41], mental health [98,99,100] and work productivity [101,102]. However, evidence-based public health guidelines are only as good as their 
implementation, which will likely be a function of the material resources both public and private organisations are willing to invest. Future research should continue to promote workers' physical and psychological wellbeing not only as a fundamental goal of public governance but also as a strategic priority for private enterprises and the continued health/wealth of such companies [102].

\section{Limitations and Future Directions}

Whilst the results of our study reveal many findings which could pose important implications for private businesses and public policy, there are important caveats to consider. It should be noted that the survey was distributed via online means. Online surveys always include uncertainties about the validity of the data, especially where the survey is self-report and if there are no published studies with a similar or same population to compare to [103]. Nonetheless, online surveys have advantages such as decreasing respondents' inhibitions, offering higher anonymity and increasing the gender, sexual orientation, and diversity of a sample [104].

In attempting to quantify the quality of wellbeing changes since the start of the lockdown, we could not rely on a standardised, validated measure that probed changes to diet, exercise, and lifestyle. We, therefore, opted to compute an aggregate score (WCI) of distinct questionnaire items on a decrease-increase scale. Despite the lack of formal validation of this scale, the observation of significant correlations between it and standardised measures of productivity (IAPT) and psychological distress (K6) is indicative of both construct and criterion validity. Future work should explore and improve the psychometric properties of this instrument.

In terms of statistical power, our study had a sample size sufficient to detect correlations of $\tau_{b}>.3$ with .8 power at an alpha of .005 but may have had less power to detect true effects for our smaller correlations at the same alpha level. We nevertheless opted to adopt this more stringent alpha level given the number of correlational tests we conducted. Whilst even the smaller correlations we observed were interpretable in light of the existing literature (and additional correlations were significant at lower alpha levels), future research should aim for larger samples to achieve greater statistical power and to possibly enable the analysis of individual differences. Indeed, in recruiting larger samples, future studies should seek to differentiate the type of remote worker occupation enabling fuller 
analysis of the particular struggles of different worker groups [8]. In addition, adding focusgroup or semi-structured interview methods would add to the robustness, richness, and depth of any findings $[105,106]$, especially concerning a novel topic such as this. Indeed, to our knowledge, this is the first study that considers a comprehensive overview of wellbeing and its effects on remote-working productivity in a UK population.

\section{Conclusion}

The mass switch to working remotely during the COVID-19 lockdowns, and the many worries stemming from the pandemic, have been argued to adversely affect the physical and mental wellbeing of workforces globally. The results of the current study demonstrate that wellbeing, which has a significant impact on productivity, is at stake when it comes to working remotely during a pandemic. The main findings of the current study were a relationship between sedentary behaviour and poorer mental health, with negative effects on work productivity, as well as challenges to productive remote working ranging from IT provisions to parental obligations were observed. Therefore, policies that promote physical activity, reduce psychological distress, address gender gaps, and support balancing childcare/home schooling whilst remote working are urgent. It is also essential that employers monitor workers' wellbeing and implement systemic guidelines and practices to maintain worker wellbeing (e.g., encouraging physically active breaks, providing more logistic support), while also promoting individual lifestyle changes (e.g., meditation, healthy cooking), as well as policy related to reasonable adjustments in the "new" workplace and clear productivity expectations. Targeted strategies such as these, to support people working remotely as a consequence of COVID-19 may help to thwart, or at least attenuate, an international public health crisis. To this end, findings from wellbeing research also need to be made easily accessible to remote workers and companies.

\section{References}

1. Fernandes, N. (2020). Economic effects of coronavirus outbreak (COVID-19) on the world economy. SSRN. https://ssrn.com/abstract=3557504 
2. Altig, D., Baker, S., Barrero, J. M., Bloom, N., Bunn, P., Chen, S., ... \& Mizen, P. (2020). Economic uncertainty before and during the COVID-19 pandemic. Journal of Public Economics, 104274. PMID: 32921841. DOI:10.1016/j.jpubeco.2020.104274

3. International Labour Organization (2020a). COVID-19 and global supply chains: How the jobs crisis propagates across borders. Retrieved from: https://www.ilo.org/global/research/policybriefs/WCMS 749368/lang--en/index.htm

4. Dang, A. K., Le, X. T. T., Le, H. T., Tran, B. X., Do, T. T. T., Phan, H. T. B., ... \& Ho, R. C. (2020). Evidence of COVID-19 impacts on occupations during the first Vietnamese national Lockdown. Annals of Global Health, 86(1). PMID:32944509. DOI:10.5334/aogh.2976

5. Mustajab, D., Bauw, A., Rasyid, A., Irawan, A., Akbar, M. A., \& Hamid, M. A. (2020). Working from Home Phenomenon as an Effort to Prevent COVID-19 Attacks and Its Impacts on Work Productivity. TIJAB (The International Journal of Applied Business),4(1), 13-21. DOI: 10.20473/tijab.V4.I1.2020.13-21

6. Ozimek, A. (2020). The future of remote work. SSRN. https://ssrn.com/abstract=3638597

7. Hadden, J., Casado, L., Sonnemaker, T., \& Borden, T. (2020, October). 20 major companies that have announced employees can work remotely long-term. Business Insider. Retrieved from: https://www.businessinsider.com/companies-asking-employees-to-work-from-home-due-tocoronavirus-2020

8. Tronco Hernández, Y. A. (2020). Remote Workers During the COVID-19 Lockdown. What Are We Missing and Why Is Important. Journal of Occupational and Environmental Medicine, 62(11), e669e672. PMID:32925524. DOI:10.1097/JOM.0000000000002018

9. Kramer, A., \& Kramer, K. Z. (2020). The potential impact of the Covid-19 pandemic on occupational status, work from home, and occupational mobility. Journal of Vocational Behavior, 119, 103442. PMID:32390661

10. Office for National Statistics (2020). Coronavirus and homeworking in the UK: April 2020 Homeworking patters in the UK, broken down by sex, age, region and ethnicity. Retrieved from https://www.ons.gov.uk/employmentandlabourmarket/peopleinwork/employmentandemployeet ypes/bulletins/coronavirusandhomeworkingintheuk/april2020

11. White, D. R. (2019). Agency Theory and Work from Home. Labour, 33(1), 1-25. DOI: 10.1111/labr.12135 
12. Hunter, P. (2019). Remote working in research: An increasing usage of flexible work arrangements can improve productivity and creativity. EMBO reports, 20(1), e47435. PMID:30530631. DOI: 10.15252/embr.201847435

13. Béland, L-P., Brodeur, A., \& Wright, T. (2020) The Short-Term Economic Consequences of Covid19: Exposure to Disease, Remote Work and Government Response. IZA Discussion Paper No. 13159. SSRN. https://ssrn.com/abstract=3584922

14. Maxwell, G., Rankine, L., Bell, S., \& MacVicar, A. (2007). The incidence and impact of flexible working arrangements in smaller businesses. Employee Relations, 29(2), 138-161. DOI:10.1108/01425450710719987

15. Shabanpour, R., Golshani, N., Tayarani, M., Auld, J., \& Mohammadian, A. K. (2018). Analysis of telecommuting behavior and impacts on travel demand and the environment. Transportation Research Part D: Transport and Environment, 62, 563-576. DOI:10.1016/j.trd.2018.04.003

16. He, S. Y. (2013). Does flexitime affect choice of departure time for morning home-based commuting trips? Evidence from two regions in California. Transport Policy, 25, 210-221. DOI:10.1016/j.tranpol.2012.11.003

17. Bosua, R., Gloet, M., Kurnia, S., Mendoza, A., \& Yong, J. (2012). Telework, productivity and wellbeing. Institute for a Broadband-Enabled Society.

18. Markey, R., Harris, C., Lamm, F., Kesting, S., Ravenswood, K., Simpkin, G., \& Williamson, D. (2008). Improving Productivity Through Enhancing Employee Wellbeing and Participation. Labour, Employment and Work in New Zealand.

19. Naz, F., \& Bögenhold, D. (2018). A contested terrain: Re/conceptualising the well-being of homeworkers. The Economic and Labour Relations Review,29(3), 328-345. DOI:10.1177/1035304618782052

20. Kruger, P. S. (2011). Wellbeing-the five essential elements. Applied Research in Quality of Life, 6(3), 325-328. DOI:10.1007/s11482-010-9127-1

21. Patel, V., Saxena, S., Lund, C., Thornicroft, G., Baingana, F., Bolton, P., ... \& Herrman, H. (2018). The Lancet Commission on global mental health and sustainable development. The Lancet, 392(10157), 1553-1598. PMID:30314863. DOI:10.1016/S0140-6736(18)31612-X

22. Dewey, C., Hingle, S., Goelz, E., \& Linzer, M. (2020). Supporting clinicians during the COVID-19 pandemic. Annals of Internal Medicine, 172(11), 752-753. PMID:32196544. DOI:10.7326/M20-1033 
23. Galbraith, N., Boyda, D., McFeeters, D., \& Hassan, T. (2020). The mental health of doctors during the Covid-19 pandemic. BJPsych Bulletin, 1-4. PMID:32340645. DOI:10.1192/bjb.2020.44

24. Maben, J., \& Bridges, J. (2020). Covid-19: Supporting nurses' psychological and mental health. Journal of Clinical Nursing, 29(15-16), 2742-2750. PMID:32320509. DOI:10.1111/jocn.15307

25. Moazzami, B., Razavi-Khorasani, N., Moghadam, A. D., Farokhi, E., \& Rezaei, N. (2020). COVID-19 and telemedicine: Immediate action required for maintaining healthcare providers wellbeing. Journal of Clinical Virology, 104345. PMID:32278298. DOI:10.1016/j.jcv.2020.104345

26. Banks, S., Cai, T., de Jonge, E., Shears, J., Shum, M., Sobočan, A. M., ... \& Weinberg, M. (2020). Practising ethically during COVID-19: Social work challenges and responses. International Social Work, 63(5), 569-583. DOI:10.1177/0020872820949614

27. Yin, Q., Sun, Z., Liu, T., Ni, X., Deng, X., Jia, Y., ... \& Liu, W. (2020). Posttraumatic Stress Symptoms of Health Care Workers during the Corona Virus Disease 2019 (COVID-19). Clinical Psychology \& Psychotherapy, 27(3), 384-395. PMID:32415733. DOI:10.1002/cpp.2477

28. Lim, D., Sanderson, K., \& Andrews, G. (2000). Lost productivity among full-time workers with mental disorders. The Journal of Mental Health Policy and Economics,3(3), 139-146. PMID:11967449. DOI:10.1002/mhp.93

29. Holmes, E. A., O'Connor, R. C., Perry, V. H., Tracey, I., Wessely, S., Arseneault, L., ... \& Ford, T. (2020). Multidisciplinary research priorities for the COVID-19 pandemic: a call for action for mental health science. The Lancet Psychiatry, 7(6), 547-560. PMID:32304649. DOI:10.1016/S22150366(20)30168-1

30. Neill, R. D., Blair, C., Best, P., McGlinchey, E., \& Armour, C. (2021). Media consumption and mental health during COVID-19 lockdown: a UK cross-sectional study across England, Wales, Scotland and Northern Ireland. Journal of Public Health, 1(9). PMID:33777650. DOI:10.1007/s10389-021-01506-0

31. Thompson, R. R., Garfin, D. R., Holman, E. A., \& Silver, R. C. (2017). Distress, worry, and functioning following a global health crisis: A national study of Americans' responses to Ebola. Clinical Psychological Science, 5(3), 513-521. DOI:10.1177/2167702617692030

32. Sell, T. K., Boddie, C., McGinty, E. E., Pollack, K., Smith, K. C., Burke, T. A., \& Rutkow, L. (2017). Media messages and perception of risk for Ebola virus infection, United States. Emerging Infectious Diseases, 23(1), 108. PMID:27983495. DOI:10.3201/eid2301.160589 
33. Jungmann, S. M., \& Witthöft, M. (2020). Health anxiety, cyberchondria, and coping in the current COVID-19 pandemic: Which factors are related to coronavirus anxiety? Journal of Anxiety Disorders, 102239. PMID:32502806. DOI:10.1016/j.janxdis.2020.102239

34. Fullana, M. A., Hidalgo-Mazzei, D., Vieta, E., \& Radua, J. (2020). Coping behaviors associated with decreased anxiety and depressive symptoms during the COVID-19 pandemic and lockdown. Journal of Affective Disorders, 275, 80-81. PMID:32658829. DOI:10.1016/j.jad.2020.06.027

35. Ammar, A., Brach, M., Trabelsi, K., Chtourou, H., Boukhris, O., Masmoudi, L., ... \& ECLB-COVID19 Consortium. (2020). Effects of COVID-19 home confinement on eating behaviour and physical activity: results of the ECLB-COVID19 international online survey. Nutrients, 12(6), 1583. PMID:32481594. DOI:10.3390/nu12061583

36. Abdel Massih, A. F., Ghaly, R., Amin, A., Gaballah, A., Kamel, A., Heikal, B., ... \& Eshak, K. (2020). Obese communities among the best predictors of COVID-19-related deaths. Cardiovascular Endocrinology \& Metabolism, 9(3), 102-107. PMID:32803143.

DOI:10.1097/XCE.0000000000000218

37. Almandoz, J. P., Xie, L., Schellinger, J. N., Mathew, M. S., Gazda, C., Ofori, A., ... \& Messiah, S. E. (2020). Impact of COVID-19 Stay-at-Home Orders on Weight-Related Behaviors Among Patients with Obesity. Clinical Obesity, e12386. PMID:32515555. DOI:10.1111/cob.12386

38. Dietz, W., \& Santos-Burgoa, C. (2020). Obesity and its Implications for COVID-19 Mortality. Obesity, 28(6), 1005-1005. PMID:32237206. DOI:10.1002/oby.22818

39. Department of Health and Social Care (2020). New obesity strategy unveiled as country urged to lose weight to beat coronavirus (COVID-19) and protect the NHS. Retrieved from https://www.gov.uk/government/news/new-obesity-strategy-unveiled-as-country-urged-to-loseweight-to-beat-coronavirus-covid-19-and-protect-the-nhs

40. Bauman, A., Bull, F., Chey, T., Craig, C. L., Ainsworth, B. E., Sallis, J. F., ... \& IPS Group. (2009). The international prevalence study on physical activity: results from 20 countries. International Journal of Behavioral Nutrition and Physical Activity, 6(1), 21. PMID:19335883. DOI:10.1186/1479-5868-621

41. World Health Organization (2011). Information sheet: global recommendations on physical activity for health 5 - 17 years old. Retrieved from:

https://www.who.int/dietphysicalactivity/publications/recommendations5 17years/en/ 
42. Hammami, A., Harrabi, B., Mohr, M., \& Krustrup, P. (2020). Physical activity and coronavirus disease 2019 (COVID-19): specific recommendations for home-based physical training. Managing Sport and Leisure, 1-6. DOI:10.1080/23750472.2020.1757494

43. Wallace, A. (2020). People welcome online workouts to fill gap left by shuttered gyms and studios. The Washington Post. Retrieved from:

https://www.washingtonpost.com/sports/2020/03/27/people-welcome-online-workouts-fillgap-left-by-shuttered-gyms-studios/

44. World Health Organisation (2018). Physical activity factsheet. Retrieved from: https://www.who.int/en/news-room/fact-sheets/detail/physical-activity

45. Ding, D., Lawson, K. D., Kolbe-Alexander, T. L., Finkelstein, E. A., Katzmarzyk, P. T., Van Mechelen, W., ... \& Lancet Physical Activity Series 2 Executive Committee. (2016). The economic burden of physical inactivity: a global analysis of major non-communicable diseases. The Lancet, 388(10051), 1311-1324. PMID:27475266. DOI:10.1016/S0140-6736(16)30383-X

46. Hall, G., Laddu, D. R., Phillips, S. A., Lavie, C. J., \& Arena, R. (2020). A tale of two pandemics: How will COVID-19 and global trends in physical inactivity and sedentary behavior affect one another? Progress in Cardiovascular Diseases, 64, 108. PMID:32277997.

DOI:10.1016/j.pcad.2020.04.005

47. Ricci, F., Izzicupo, P., Moscucci, F., Sciomer, S., Maffei, S., Di Baldassarre, A., ... \& Gallina, S. (2020). Recommendations for Physical Inactivity and Sedentary Behavior During the Coronavirus Disease (COVID-19) Pandemic. Frontiers in Public Health, 8, 199. PMID:32574294.

DOI:10.3389/fpubh.2020.00199

48. Roschel, H., Artioli, G. G., \& Gualano, B. (2020). Risk of Increased Physical Inactivity During COVID-19 Outbreak in Older People: A Call for Actions. Journal of the American Geriatrics Society, 68(6), 1126-1128. PMID:32392620. DOI:10.1111/jgs.16550.

49. Adams-Prassl, A., Boneva, T., Golin, M., \& Rauh, C. (2020). Inequality in the Impact of the Coronavirus Shock: Evidence from Real Time Surveys. CEPR Discussion Paper No. DP14665. SSRN. https://ssrn.com/abstract=3594297

50. Institute for Government (2020). Coronavirus lockdown rules in each part of the UK. Retrieved from https://www.instituteforgovernment.org.uk/explainers/coronavirus-lockdown-rules-fournations-uk

51. Kessler, R. C., Andrews, G., Colpe, L. J., Hiripi, E., Mroczek, D. K., Normand, S. L., ... \& Zaslavsky, A. M. (2002). Short screening scales to monitor population prevalences and trends in non-specific 
psychological distress. Psychological Medicine, 32(6), 959-976. PMID:12214795.

DOI:10.1017/s0033291702006074

52. Prochaska, J. J., Sung, H. Y., Max, W., Shi, Y., \& Ong, M. (2012). Validity study of the K6 scale as a measure of moderate mental distress based on mental health treatment need and utilization. International Journal of Methods in Psychiatric Research,21(2), 88-97. PMID:22351472. DOI:10.1002/mpr.1349

53. Mäder, U. R. S., Martin, B. W., Schutz, Y., \& Marti, B. (2006). Validity of four short physical activity questionnaires in middle-aged persons. Medicine and Science in Sports and Exercise, 38(7), 1255. PMID:16826022. D0I:10.1249/01.mss.0000227310.18902.28

54. Craig, C. L., Marshall, A. L., Sjöström, M., Bauman, A. E., Booth, M. L., Ainsworth, B. E., ... \& Oja, P. (2003). International physical activity questionnaire: 12-country reliability and validity. Medicine \& Science in Sports \& Exercise, 35(8), 1381-1395. PMID:12900694.

DOI:10.1249/01.MSS.0000078924.61453.FB

55. Jetté, M., Sidney, K., \& Blümchen, G. (1990). Metabolic equivalents (METS) in exercise testing, exercise prescription, and evaluation of functional capacity. Clinical Cardiology, 13(8), 555-565. PMID:2204507. DOI:10.1002/clc.4960130809

56. Mansoubi, M., Pearson, N., Biddle, S. J., \& Clemes, S. (2014). The relationship between sedentary behaviour and physical activity in adults: a systematic review. Preventive Medicine, 69, 28-35. PMID:25193005. DOI:10.1016/j.ypmed.2014.08.028

57. Mannocci, A., Di Thiene, D., Del Cimmuto, A., Masala, D., Boccia, A., De Vito, E., \& La Torre, G. (2010). International Physical Activity Questionnaire: validation and assessment in an Italian sample. Italian Journal of Public Health, 7(4). DOI:10.2427/5694

58. Sprada de Menezes, F., \& de Paula Xavier, A. A. (2018). Development, Validation, and Reliability Testing of the Brief Instrument to Assess Workers Productivity during a Working Day (IAPT). Revista Brasileira de Gestão de Negócios, 20(2). DOI:10.7819/rbgn.v20i2.3764

59. Kessler, R. C., Barber, C., Beck, A., Berglund, P., Cleary, P. D., McKenas, D., ... \& Wang, P. (2003). The World Health Organization Health and Work Performance Questionnaire (HPQ).Journal of Occupational and Environmental Medicine, 45(2), 156-174. PMID:12625231. DOI:10.1097/01.jom.0000052967.43131.51

60. Hsieh, H. F., \& Shannon, S. E. (2005). Three approaches to qualitative content analysis. Qualitative Health Research, 15(9), 1277-1288. PMID:16204405. DOI:10.1177/1049732305276687 
61. Zhang, Y. \& Wildemuth, B. (2009). Unstructured Interviews. In Wildemuth, B. (Ed), Applications of Social Research Methods to Questions in Information and Library Science (2nd ed.), pp. 239-247. ISBN:978-1591585039

62. Lietz, C. A., Langer, C. L., \& Furman, R. (2006). Establishing trustworthiness in qualitative research in social work: Implications from a study regarding spirituality. Qualitative Social Work, 5(4), 441-458. DOI:10.1177/1473325006070288

63. Bryant, L., Garnham, B., Tedmanson, D., \& Diamandi, S. (2018). Tele-social work and mental health in rural and remote communities in Australia. International Social Work, 61(1), 143-155. DOI:10.1177/0020872815606794

64. Kunii, Y., Suzuki, Y., Shiga, T., Yabe, H., Yasumura, S., Maeda, M., ... \& Mental Health Group of the Fukushima Health Management Survey. (2016). Severe psychological distress of evacuees in evacuation zone caused by the Fukushima Daiichi Nuclear Power Plant accident: the Fukushima Health Management Survey. PLoS One, 11(7), e0158821. PMID:27391446. DOI:10.1371/journal.pone.0158821

65. Bialowolski, P., McNeely, E., VanderWeele, T. J., \& Weziak-Bialowolska, D. (2020). Ill health and distraction at work: Costs and drivers for productivity loss. PloS One, 15(3), e0230562. PMID:32231382. DOI:10.1371/journal.pone.0230562

66. Bubonya, M., Cobb-Clark, D. A., \& Wooden, M. (2017). Mental health and productivity at work: Does what you do matter? Labour Economics, 46, 150-165. DOI:10.1016/j.labeco.2017.05.001

67. Hilton, M. F., Scuffham, P. A., Vecchio, N., \& Whiteford, H. A. (2010). Using the interaction of mental health symptoms and treatment status to estimate lost employee productivity. Australian \& New Zealand Journal of Psychiatry, 44(2), 151-161. PMID:20113304.

DOI:10.3109/00048670903393605

68. World Health Organisation (2014). Global status report on noncommunicable disease - Attaining the nine global noncommunicable diseases targets; a shared responsibility. Retrieved from https://www.who.int/nmh/publications/ncd-status-report-2014/en/

69. Di Renzo, L., Gualtieri, P., Pivari, F., Soldati, L., Attinà, A., Cinelli, G., ... \& Esposito, E. (2020). Eating habits and lifestyle changes during COVID-19 lockdown: an Italian survey. Journal of Translational Medicine, 18(1), 1-15. PMID:32513197. DOI:10.1186/s12967-020-02399-5

70. Vaara, J. P., Vasankari, T., Koski, H. J., \& Kyröläinen, H. (2019). Awareness and knowledge of physical activity guidelines in young adult men. Frontiers in Public Health, 7, 310. PMID:31737590. DOI:10.3389/fpubh.2019.00310 
71. Chen, P., Mao, L., Nassis, G. P., Harmer, P., Ainsworth, B. E. \& Li, F. (2020). Coronavirus disease (COVID-19): The need to maintain regular physical activity while taking precautions. Journal of Sport and Health Science, 9, 103-104. PMID:32099716. DOI:10.1016/j.jshs.2020.02.001

72. Zhu, W. (2020). Should, and how can, exercise be done during a coronavirus outbreak? An interview with Dr. Jeffrey A. Woods. Journal of Sport and Health Science, 9, 105-107. PMID:32099717. DOI:10.1016/j.jshs.2020.01.005

73. Dockery, A. M., \& Bawa, S. (2014). Is working from home good work or bad work? Evidence from Australian employees. Australian Journal of Labour Economics, 17(2), 163. ISSN:12381143

74. Felstead, A., \& Jewson, N. (2000). In work, at home: Towards an understanding of homeworking. Psychology Press. ISBN:9780415163002

75. Sullivan, C., \& Smithson, J. (2007). Perspectives of homeworkers and their partners on working flexibility and gender equity. The International Journal of Human Resource Management, 18(3), 448461. DOI:10.1080/09585190601167797

76. Churchill, F. (2020). Half working from home during lockdown are unhappy with work-life balance, survey finds. Available at: https://www.peoplemanagement.co.uk/news/articles/halfworking-from-home-during-lockdown-unhappy-with-work-life-balance. Accessed on 19 April 2020 77. Richardson, M., McEwan, K., Maratos, F., \& Sheffield, D. (2016). Joy and calm: How an evolutionary functional model of affect regulation informs positive emotions in nature. Evolutionary Psychological Science, 2(4), 308-320. DOI:10.1007/s40806-016-0065-5

78. Wilson, A. C., Mackintosh, K., Power, K., \& Chan, S. W. (2019). Effectiveness of self-compassion related therapies: A systematic review and meta-analysis. Mindfulness, 10(6), 979-995. DOI:10.1007/s12671-018-1037-6

79. Appiah-Mfodwa, A., Horwitz, F., Kieswetter, G., King, D., \& Solai, L. (2000). Flexible work practices, productivity improvement and employment. Society in Transition,31(2), 95-110. DOI:10.1080/21528586.2000.10419016

80. Maratos, F. A., Montague, J., Ashra, H., Welford, M., Wood, W., Barnes, C., ... \& Gilbert, P. (2019). Evaluation of a compassionate mind training intervention with school teachers and support staff. Mindfulness, 10(11), 2245-2258. DOI:10.1007/s12671-019-01185-9

81. International Labour Organization (2020b). Working from home: Estimating the worldwide potential. Retrieved from: https://www.ilo.org/global/topics/non-standardemployment/publications/WCMS 743447/lang--en/index.htm 
82. International Labour Organization (2020c). Delivering income and employment support in times of COVID-19: Integrating cash transfers with active labour market policies. Retrieved from: https://www.ilo.org/global/research/publications/WCMS 748331/lang--en/index.htm

83. Savić, D. (2020). COVID-19 and Work from Home: Digital Transformation of the Workforce. Grey Journal (TGJ), 16(2).

84. Godinic, D., Obrenovic, B., \& Khudaykulov, A. (2020). Effects of Economic Uncertainty on Mental Health in the COVID-19 Pandemic Context: Social Identity Disturbance, Job Uncertainty and Psychological Well-Being Model. International Journal of Management Science and Business Administration, 6(1), 61-74.

85. Lange, K. W. (2018). Diet, exercise, and mental disorders - public health challenges of the future. Movement and Nutrition in Health and Disease, 2. DOI:10.5283/mnhd.12

86. Health and Safety Executive (2021, April). Social distancing to make your workplace COVIDsecure. Retrieved from: https://www.hse.gov.uk/coronavirus/social-distancing/index.htm

87. Slack Future Forum (2020, October). Moving beyond remote: Workplace transformation in the wake of Covid-19. Retrieved from: https://slack.com/intl/en-gb/blog/collaboration/workplacetransformation-in-the-wake-of-covid-19

88. Tan, W., Hao, F., McIntyre, R. S., Jiang, L., Jiang, X., Zhang, L., ... \& Tam, W. (2020). Is returning to work during the COVID-19 pandemic stressful? A study on immediate mental health status and psychoneuroimmunity prevention measures of Chinese workforce.Brain, behavior, and immunity, 87, 84-92. PMID:32335200. D0I:10.1016/j.bbi.2020.04.055

89. Rimmer, A. (2020). How can I keep calm during self-isolation? BMJ, 369. PMID:32241760. DOI:10.1136/bmj.m1376

90. Larson, B. Z., Vroman, S. R., \& Makarius, E. E. (2020). A guide to managing your (newly) remote workers. Harvard Business Review, 18.

91. Farré, L., Fawaz, Y., González, L., \& Graves, J. (2020). How the covid-19 lockdown affected gender inequality in paid and unpaid work in Spain. IZA Discussion Paper No. 13434, Institute of Labor Economics (IZA), Bonn. Retrieved from:

https://www.econstor.eu/bitstream/10419/223876/1/dp13434.pdf

92. Hawkes, C. (2020). Five steps towards a global reset: lessons from COVID-19. Global Sustainability, 3. DOI:10.1017/sus.2020.24 
93. Rodríguez-Pérez, C., Molina-Montes, E., Verardo, V., Artacho, R., García-Villanova, B., GuerraHernández, E. J., \& Ruíz-López, M. D. (2020). Changes in Dietary Behaviours during the COVID-19 Outbreak Confinement in the Spanish COVIDiet Study. Nutrients, 12(6), 1730. PMID:32531892. DOI: $10.3390 /$ nu12061730

94. Netea, M. G., Giamarellos-Bourboulis, E. J., Domínguez-Andrés, J., Curtis, N., van Crevel, R., van de Veerdonk, F. L., \& Bonten, M. (2020). Trained Immunity: A Tool for Reducing Susceptibility to and the Severity of SARS-CoV-2 Infection. Cell, 181(5), 969-977. PMID:32437659. DOI:10.1016/j.cell.2020.04.042

95. Zabetakis, I., Lordan, R., Norton, C., \& Tsoupras, A. (2020). COVID-19: The Inflammation Link and the Role of Nutrition in Potential Mitigation. Nutrients, 12(5), 1466. PMID:32438620. DOI:10.3390/nu12051466

96. Hawkes, C., Jewell, J., \& Allen, K. (2013). A food policy package for healthy diets and the prevention of obesity and diet-related non-communicable diseases: the NOURISHING framework. Obesity Reviews, 14, 159-168. DOI:24103073. DOI:10.1111/obr.12098

97. Tiwari, A., Aggarwal, A., Tang, W., \& Drewnowski, A. (2017). Cooking at home: a strategy to comply with US dietary guidelines at no extra cost. American Journal of Preventive Medicine, 52(5), 616-624. PMID:28256283. DOI:10.1016/j.amepre.2017.01.017

98. Zhao, Y., An, Y., Tan, X., \& Li, X. (2020). Mental Health and Its Influencing Factors among SelfIsolating Ordinary Citizens during the Beginning Epidemic of COVID-19. Journal of Loss and Trauma, 1-14. DOI:10.1080/15325024.2020.1761592

99. Pang Tze Ping, N., Shoesmith, W. D., James, S., Nor Hadi, N. M., Koh Boon Yau, E., \& Lin, L. J. (2020). Ultra Brief Psychological Interventions for COVID-19 Pandemic: Introduction of a LocallyAdapted Brief Intervention for Mental Health and Psychosocial Support Service. Malaysian Journal of Medical Sciences, 27(2). PMID:32788841. DOI:10.21315/mjms2020.27.2.6

100. Altena, E., Baglioni, C., Espie, C. A., Ellis, J., Gavriloff, D., Holzinger, B., ... \& Riemann, D. (2020). Dealing with sleep problems during home confinement due to the COVID-19 outbreak: Practical recommendations from a task force of the European CBT-I Academy. Journal of Sleep Research, e13052. PMID:32246787. DOI:10.1111/jsr.13052

101. Kaur, H., Williams, A. C., McDuff, D., Czerwinski, M., Teevan, J., \& Iqbal, S. T. (2020, April). Optimizing for Happiness and Productivity: Modeling Opportune Moments for Transitions and Breaks at Work. In Proceedings of the 2020 CHI Conference on Human Factors in Computing Systems (pp. 1-15). DOI:10.1145/3313831.3376817 
102. Pronk, N. P., \& Kottke, T. E. (2009). Physical activity promotion as a strategic corporate priority to improve worker health and business performance. Preventive Medicine, 49(4), 316-321. PMID:19589352. DOI:10.1016/j.ypmed.2009.06.025

103. Wright, K. B. (2005). Researching Internet-based populations: Advantages and disadvantages of online survey research, online questionnaire authoring software packages, and web survey services. Journal of Computer-Mediated Communication, 10(3), JCMC1034. DOI:10.1111/j.10836101.2005.tb00259.x

104. Boydell, N., Fergie, G., McDaid, L., \& Hilton, S. (2014). Avoiding pitfalls and realising opportunities: Reflecting on issues of sampling and recruitment for online focus groups. International Journal of Qualitative Methods,13(1), 206-223. PMID:28127272. DOI:10.1177/160940691401300109

105. Cohen, D., \& Crabtree, B. (2006). Qualitative Research Guidelines Project.[online] Available at: http://www.qualres.org/HomeInfo-3631.html

106. Pelto, P. J., \& Pelto, G. H. (1978). Anthropological research: The structure of inquiry. Cambridge University Press. ISBN:9780521292283 